\title{
The urgency of measuring fluorinated greenhouse gas emission factors from the treatment of textile and other substrates
}

\author{
Andrea Zille ${ }^{1,2^{*} \dagger}$, Sébastien Raoux ${ }^{1,3 \dagger}$ \\ ${ }^{1}$ Intergovernmental Panel on Climate Change (IPCC) Lead Author of the 2019 \\ Refinement to the 2006 IPCC Guidelines for National Greenhouse Gas Inventories \\ (Volume 3, Chapter 8: Textile, carpet, leather and paper fluorinated treatment \\ emissions). \\ ${ }^{2}$ Principal Investigator at the Centre for Textile Science and Technology (2C2T), \\ University of Minho, Guimarães, Portugal. \\ ${ }^{3}$ President \& Chief Executive Officer (CEO) Transcarbon International, New York, \\ USA. \\ *Correspondence to: azille@2c2t.uminho. \\ $\dagger$ Equal contributions.
}

The fashion industry is responsible for up to $10 \%$ of global $\mathrm{CO}_{2}$ emissions, and according to the United Nations Framework Convention on Climate Change (UNFCCC), the sector's emissions are expected to rise by more than $60 \%$ by $2030(1-5)$. While the vast majority of the sector's carbon footprint results from $\mathrm{CO}_{2}$ emissions, an additional source - still unaccounted for and growing - likely results from emissions of fluorinated greenhouse gases (F-GHGs) during the treatment of textile and leather. Indeed, fluorinebased treatment of fibers and other substrates (paper, metals, plastics, etc.) is increasingly performed using wet- or plasma-based methods to functionalize surfaces for water and oil repellence, soil and stain release, improved textile breathability, softening, dyeing ability, increased mechanical strength, reduced adherence, antibacterial and anti-odor properties, and to fabricate wrinkle-free materials (6).

Although F-GHG emissions only represent $2.6 \%$ of global greenhouse gas emissions, FGHGs have long atmospheric life (up to 50,000 years for $\mathrm{CF}_{4}$ ) and high global warming potential (GWP, up to 23,500 for $\mathrm{SF}_{6}$ ) (7). Thus, it is concerning that the atmospheric concentration of some of these gases is higher than what is predicted through bottom-up analyses (8). During the 2015-2016 Technical Assessment of the 2006 IPCC Guidelines for National GHG Inventories, potential emissions from the textile industry were accounted, among others, as a possible reason for the gap between top-down and bottomup estimates of F-GHG emissions (9). Surprisingly, although several international and national reports refer to possible atmospheric emissions of F-GHGs during finishing of textile, carpet, leather, and paper, no corresponding emission factors were found to have been measured and published in the open literature ( 6 ).

Fluorinated wet treatment processes include several application techniques but about $80 \%$ of the processes use the pad-dry-cure method, where the dry fabric is immersed in a Fbased finishing liquor and then squeezed between rollers before being dried and finally cured, usually at temperatures up to $180{ }^{\circ} \mathrm{C}$. Chemicals used for wet treatment processes include fluorotelomer alcohols, and perfluoroalkyl carboxylic acids. Although such 
chemicals may not be GHGs by themselves, it is unclear whether fluorinated ethers, unreacted monomers or by-products formed during the deposition processes, and in the atmosphere, can produce relevant F-GHGs (10). Notwithstanding, it has been proved that during the drying and curing phases, F-based off-gas emissions can be produced by the volatility of the active substances themselves as well as by their constituents through evaporative losses and cracking (11). Moreover, high-GWP perfluoropolyethers were identified as being used in a number of commercial applications, including for textile treatment, increasing the concerns about the atmospheric release of these compounds (11, 12).

Recently, due to the persistent and bio-accumulative nature of the chemicals used in wet processes, several manufacturers have developed alternate plasma-based treatments for specialized fibers and substrates $(6,13)$. Plasma technology can be tailored to achieve many desirable properties and may provide equal or even better performance than wet methods. ${ }^{5}$ Plasma processes can be divided into three process types: 1) plasma treatment, 2) plasma polymerization and 3) plasma etching. Plasma treatment and polymerization are the main processes of concern because they can use large quantities of F-GHG feedstocks such as $\mathrm{CF}_{4}, \mathrm{C}_{2} \mathrm{~F}_{6}, \mathrm{C}_{3} \mathrm{~F}_{8}, \mathrm{C}_{4} \mathrm{~F}_{8}, \mathrm{C}_{5} \mathrm{~F}_{10}, \mathrm{CHF}_{3}, \mathrm{SF}_{6}$, and other larger molecules such as perfluoroalkyl acrylates to deposit thin films on a substrate. Because the application of high plasma power densities could damage fragile substrates, it is highly probable that feedstock molecules are not fully disassociated by the plasma. Further, the plasma disassociation of F-GHGs is well known to result in the formation of other FGHG byproducts (e.g. of $\mathrm{CF}_{4}$ from $\left.\mathrm{C}_{2} \mathrm{~F}_{6}\right)(8,14)$. Therefore, plasma-based fluorinated treatment of textile, carpet, leather, paper, and other substrates is expected to lead to higher F-GHG emissions than wet chemistry methods.

The authors of the 2019 Refinement to the 2006 IPCC Guidelines for National Greenhouse Gas Inventories have proposed four distinct tiered methods (Tier 1, Tier 2a, Tier $2 b$, and Tier 3 ) to account for emissions from wet- and plasma-based fluorinated treatment of textile, leather, carpet, and paper (6). However, because no Tier 1 or Tier 2 default (industry average) factors are available, only the Tier 3 method is practicable, using equipment-specific, process-specific, or site-specific measured emission factors. Measurements should preferentially be performed by Fourier transform infrared spectroscopy (FTIR) due to part per billion (ppb) sensitivity and portability or by gas chromatography followed by mass spectrometry (GC/MS), allowing near real time measurements.

Emissions of F-GHGs from wet- and plasma-based fluorinated treatment of textile, leather, paper fibers, and other substrates may be substantial due to the large volume of materials treated and the sheer size and global nature of these industrial sectors. It is therefore urgent to measure the corresponding emissions factors and to create a comprehensive international database of such factors in order to estimate emissions from these sources.

\section{References}

1. [Editorial], The price of fast fashion. Nature Climate Change 8, 1-1 (2018).

2. K. Niinimäki et al., The environmental price of fast fashion. Nature Reviews Earth \& Environment 1, 189-200 (2020).

3. [Press-Release]. (United Nations Framework Convention on Climate Change 2018). 
4. [Report], "Measuring Fashion: Environmental Impact of the Global Apparel and Footwear Industries Study," (Quantis, 2018).

5. [Report], "A new textiles economy: Redesigning fashion's future," (Ellen MacArthur Foundation, 2017).

6. A. Zille, S. Raoux, in 2019 Refinement to the 2006 IPCC Guidelines for National Greenhouse Gas Inventories. (Intergovernmental Panel on Climate Change (IPCC), Geneva, Switzerland, 2019), vol. 3: Industrial Processes and Product Use.

7. [Report], "Emissions Gap Report," (United Nations Environment Programme (UNEP) and UNEP DTU Partnership (UDP), Nairobi, Kenya, 2020).

8. J. Kim et al., Quantifying aluminum and semiconductor industry perfluorocarbon emissions from atmospheric measurements. Geophysical Research Letters 41, 4787-4794 (2014).

9. [Report], "Report of IPCC Scoping Meeting for a Methodology Report(s) to refine the 2006 IPCC Guidelines for National Greenhouse Gas Inventories," (IPCC, Japan, 2016).

10. F. Heydebreck, J. Tang, Z. Xie, R. Ebinghaus, Emissions of Per- and Polyfluoroalkyl Substances in a Textile Manufacturing Plant in China and Their Relevance for Workers' Exposure. Environmental Science \& Technology 50, 10386-10396 (2016).

11. [Report], "Emission Scenario Document on Textile Finishing Industry ENV/JM/MONO(2004)12," OECD Series on Emission Scenario Documents No. 7 (Organization for Economic Co-operation and Development (OCDE), Paris, France, 2004).

12. C. J. Young, M. D. Hurley, T. J. Wallington, S. A. Mabury, Atmospheric Lifetime and Global Warming Potential of a Perfluoropolyether. Environmental Science \& Technology 40, 2242-2246 (2006).

13. C. Tudoran, M. C. Roşu, M. Coroş, A concise overview on plasma treatment for application on textile and leather materials. Plasma Processes and Polymers 17, (2020).

14. [Report], "Industrial Processes and Product Use," (Intergovernmental Panel on Climate Change (IPCC), Geneva, Switzerland, 2019).

Acknowledgments: The authors would like to thank you the Intergovernmental Panel on Climate Change (IPCC) for the invitation as Lead author to contribute in the 2019 Refinement to the 2006 Intergovernmental Panel on Climate Change (IPCC) Guidelines for National Greenhouse Gas Inventories (Volume 3, Chapter 8: Textile, carpet, leather and paper fluorinated treatment emissions).

Funding: Andrea Zille acknowledges the Centro de Ciência e Tecnologia Têxtil (2C2T) of the Universidade do Minho for the travel expenses reimbursement through the project UID/CTM/00264/2019 of the Portuguese Fundação para a Ciência e Tecnologia (FCT).

Author contributions: The authors have equally contributed to the work development.

Competing interests: Andrea Zille declare no financial conflict of interest but as Senior Researcher at the University of Minho, He have co-authored the 2019 Refinement to the 2006 Intergovernmental Panel on Climate Change (IPCC) Guidelines for National Greenhouse Gas Inventories (Volume 3, Chapter 8: Textile, carpet, leather and paper fluorinated treatment emissions) which are directly connected to the opinions expressed in the proposed manuscript. More information is disclosed in the submitted Conflict of Interest form. 